\title{
Nanoparticle formation in the exhaust of vehicles running on ultra-low sulfur fuel
}

\author{
H. Du and F. Yu \\ Atmospheric Sciences Research Center, State University of New York at Albany, Albany, NY 12203, USA \\ Received: 3 January 2008 - Published in Atmos. Chem. Phys. Discuss.: 12 February 2008 \\ Revised: 1 July 2008 - Accepted: 18 July 2008 - Published: 18 August 2008
}

\begin{abstract}
The concern of adverse health impacts from exposure to vehicle-emitted nanoparticles has been escalating over the past few years. In order to meet more stringent EPA emission standards for particle mass emissions, advanced exhaust after-treatment systems such as continuously regenerating diesel particle filters (CRDPFs) have to be employed on vehicles and fuel with ultra-low sulfur is to be used. Although CRDPFs were found to be effective in reducing particle mass emissions, they were revealed to increase the potential of volatile nanoparticle formation. Significant nanoparticle concentrations have also been detected for vehicles running on ultra-low sulfur fuel but without CRDPFs. The main focus of this paper is the formation and evolution of nanoparticles in an exhaust plume under ultra-low sulfur conditions. Such a study is necessary to project future nanoparticle emissions as fuel compositions and aftertreatment systems change. We have carried out a comprehensive quantitative assessment of the effects of enhanced sulfur conversion efficiency, sulfur storage/release, and presence of non-volatile cores on nanoparticle formation using a detailed composition resolved aerosol microphysical model with a recently improved $\mathrm{H}_{2} \mathrm{SO}_{4}-\mathrm{H}_{2} \mathrm{O}$ homogeneous nucleation (BHN) module. Two well-controlled case studies show good agreement between model predictions and measurements in terms of particle size distribution and temperature dependence of particle formation rate, which leads us to conclude that BHN is the main source of nanoparticles for vehicles equipped with CRDPFs. We found that the employment of CRDPFs may lead to the higher number concentration of nanoparticles (but smaller size) in the exhaust of vehicles running on ultra-low sulfur fuel compared to those emitted from vehicles running on high sulfur fuel. We have also shown that the sulfate storage and release effect can lead
\end{abstract}

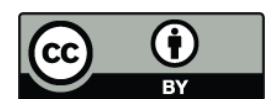

Correspondence to: $\mathrm{H}$. Du (huadu@asrc.cestm.albany.edu) to significant enhancement in nanoparticle production under favorable conditions. For vehicles running on ultra-low sulfur fuel but without CRDPFs, the BHN is negligible; however, the condensation of low volatile organic compounds on nanometer-sized non-volatile cores may explain the observed nucleation mode particles.

\section{Introduction}

Vehicle emission is one of the major sources of nanoparticles in urban areas. A large number of studies in the past few years have associated nanoparticles with adverse public health effects (Wold et al., 2006; Carbajal-Arroyo et al., 2007; Gauderman et al., 2007; Meng et al., 2007; Rundell et al., 2007). Therefore, a clear understanding of onroad nanoparticle formation and subsequent near-road evolution is critically important for the quantitative assessment of nanoparticle exposure levels to travelers on roadways and residents living nearby. Diesel vehicles are known to be one of the major sources of the particulate matter near busy roads. Recently, continuously regenerating diesel particle filters (CRDPFs) have been shown to be able to reduce particulate matter emission by orders of magnitude. However, their effect on the nanoparticle formation remains unclear. It is also important to know the extent to which CRDPF affects the production of nanoparticles formed via the combustion of ultra-low sulfur fuels.

Nanoparticle formation in vehicular exhaust is a complex process whose rate depends strongly on a number of factors including the sulfur content in fuel and lubricating oil, engine operation conditions, exhaust after-treatment setups, ambient conditions and exhaust dilution. Binary $\mathrm{H}_{2} \mathrm{SO}_{4}$ $\mathrm{H}_{2} \mathrm{O}$ homogeneous nucleation (BHN) theory has been applied to study nucleation in diesel exhaust. It has been shown that in the high sulfur fuel conditions (i.e. fuel sulfur content (FSC) $>300 \mathrm{ppm}$ ), BHN may account for formation of

Published by Copernicus Publications on behalf of the European Geosciences Union. 
vehicle-emitted nanoparticles (Du and Yu, 2006). Lemmetty et al. (2006) also applied the classical BHN model to study maximum $\mathrm{H}_{2} \mathrm{SO}_{4}-\mathrm{H}_{2} \mathrm{O}$ nucleation rates in diesel exhaust assuming the sulfur to sulfuric acid conversion efficiency of $100 \%$ and exhaust temperature of $\sim 400 \mathrm{~K}$. It is important to note that Lemmetty et al. (2006) may have over predicted maximum nucleation rates because the exhaust temperature of $>\sim 700 \mathrm{~K}$ is needed in order to achieve a $100 \%$ conversion efficiency (Giechaskiel et al., 2007).

At the present time, the fuel sulfur content (FSC) for diesel vehicles has been reduced from $\sim 500 \mathrm{ppm}$ to $15 \mathrm{ppm}$ (by weight) nationwide. The role of BHN in nanoparticle formation in ultra-low sulfur conditions (i.e. FSC $\sim 15 \mathrm{ppm}$ ) is expected to be negligible ( $\mathrm{Du}$ and $\mathrm{Yu}, 2006$ ) due to the nonlinear dependence of nucleation rates on $\mathrm{H}_{2} \mathrm{SO}_{4}$ concentration,. However, many recent laboratory experiments and in situ measurements have shown that number concentrations of nanoparticles emitted by vehicles running on the ultra-low sulfur fuel are unexpectedly high (Maricq et al., 2002; Vaaraslahti et al., 2004, 2005; Arnold et al., 2006; Kittelson et al., 2006; Giechaskiel et al., 2007; Rönkkö et al., 2007). This suggests that the application of CRDPFs may have profound effects on the observed nanoparticle formation. In the presence of CRDPFs, the nucleation mode was found to be sensitive to FSC and the largest ( $90 \%)$ mass of nucleation mode particles was found to be sulfate (Kittelson et al., 2006). This suggests that BHN may be involved in the nanoparticle formation mechanism under the aforementioned conditions. Two possible reasons for the influence of CRDPFs on nanoparticle formation can be identified: (a) enhanced sulfur conversion efficiency $(\varepsilon)$ due to CRDPFs (Maricq et al., 2002; Vaaraslahti et al., 2004; Arnold et al., 2006; Kittelson et al., 2006; Giechaskiel et al., 2007); The use of oxidation catalyst in CRDPFs will oxidize more $\mathrm{SO}_{2}$ into $\mathrm{SO}_{3}$, which eventually turns into a higher $\mathrm{H}_{2} \mathrm{SO}_{4}$ concentration. This makes it possible for BHN to produce nanoparticles even under ultra-low sulfur conditions; (b) sulfur storage/release effect (Arnold et al., 2006; Giechaskiel et al., 2007). Sulfate that originally deposits on the tailpipe or surface of oxidation catalyst/filters may evaporate back into the exhaust due to saturation of storage sites and/or vehicle acceleration. This will increase in-exhaust $\mathrm{H}_{2} \mathrm{SO}_{4}$ concentration which in turn affects nanoparticle formation. On the other hand, in the absence of CRDPFs the number concentration of the nucleation mode particles was found to be independent of FSC (Vaaraslahti et al., 2004; Rönkkö et al., 2007). The sampled nanoparticles were shown to have non-volatile cores coated with organics (Rönkkö et al., 2007). Although numerous experimental studies have demonstrated the importance of different factors on the nanoparticle production, the formation mechanisms behind the elevated nanoparticle production remain elusive. In the present paper, the effect of the above-mentioned factors (enhanced sulfur conversion efficiency, sulfur storage/release, and presence of non-volatile cores) on the nanoparticle formation in the presence or absence of CRDPFs has been studied using the size and composition resolved aerosol microphysical model. The major objective of the present study is to investigate the formation mechanism for nanoparticles emitted by vehicles running on ultra low sulfur fuel by focusing on the effects of the enhanced sulfur conversion efficiency, sulfur storage/release, and presence of non-volatile cores.

\section{Method}

\subsection{Dilution of exhaust plume in the atmosphere}

In order to study the nanoparticle formation and evolution inside a single vehicular plume, the size and composition resolved aerosol model has been developed. Zhang et al. (2004) divided vehicular plume evolution into two stages: from tailpipe to roadside and from roadside to vicinity of roadway. However, in this study, three stages of plume evolution, distinguished by different dilution and dominant aerosol microphysical processes, are applied to study the nanoparticle formation and evolution. The stage 1 starts at $0 \mathrm{~s}$ (right behind the tailpipe) and ends at $1 \mathrm{~s}$ of the plume age. The plume age is defined as time elapsed after the exhaust is emitted from the tailpipe. The hot vehicular exhaust experiences rapid dilution due to strong turbulence in the near field of the tailpipe. At this stage of the plume evolution, the nucleation is the key microphysical process. Studies (Kittelson et al., 1988; Shi et al., 2002) have shown that typical dilution ratios at this stage are $\sim 1000$. The dilution ratio as a function of the plume age used in this study was obtained using the nonlinear regression of the experimental data by Kittelson et al. (1988). The dilution ratio (DR) in Kittelson et al. (1988) is expressed as $D R_{1}(t)=1+700 \times t^{1.413}\left(t=0-t_{1}\right), t_{1}$ is set to be $1.0 \mathrm{~s}$.

The stage 2 begins after $1 \mathrm{~s}$ of plume age and ends when the exhaust reaches the roadside. At this stage the low volatile organics still condense onto nucleated particles; however, semi-volatile organics may begin to evaporate due to dilution (Sakurai et al., 2003). The precise determination of the dilution ratio in a single on-road vehicle plume is a complex problem, whose solution requires accurate descriptions of the vehicle generated turbulence and mixing of the considered plume with other plumes. At the present time, no commonly accepted dispersion model can predict, with a considerable degree of confidence, the on-road dilution profile for a single plume. In the present study, the dilution profile during the stage 2 was determined as the ratio of $\mathrm{CO}_{2}$ concentration in raw exhaust before dilution to the observed on-road one. Typically, the dilution ratio at plume age of $\sim 5 \mathrm{~s}$ varies from $\sim 5$ to $\sim 10$ (relative to $t=1 \mathrm{~s}$ ), depending on traffic density, wind speed and atmospheric stability. The dilution ratio at stage 2 is expressed as $\mathrm{DR}_{2}(t)=\mathrm{DR}_{1}\left(t_{1}\right)+\left(\left(\mathrm{ODR} 2-\mathrm{DR}_{1}\left(t_{1}\right)\right) /\left(t_{2}-t_{1}\right)\right) \times\left(t-t_{1}\right)$, 
$\left(t_{1}<t \leq t_{2}\right)$, where ODR2 is the overall dilution ratio of the plume at the roadside.

The stage 3 occurs in the vicinity of the roadway (from the roadside to any downwind location perpendicular to the roadway). The aerosol processing at stage 3 involves coagulation, dilution, and/or evaporation of organics. The corresponding dilution profile can be determined from $\mathrm{CO}$ measurements. The additional dilution (relative to $t_{2}=6 \mathrm{~s}$ ) in the stage 3 is assumed to be $\sim 10$ at $150 \mathrm{~m}$ away from the roadside (Zhu et al., 2002). The plume dilution profile in this stage is expressed as $\mathrm{DR}_{3}(t)=\mathrm{DR}_{2}\left(t_{2}\right)+\left(\left(\operatorname{RDR} 3 \times \mathrm{DR}_{2}\left(t_{2}\right) /\left(t_{3}-t_{2}\right)\right) \times\left(t-t_{2}\right)\right.$, $\left(t_{2}<t \leq t_{3}\right)$, where RDR3 is the dilution ratio of stage 3 relative to the dilution ratio at the roadside $\left(D_{2}\right)$. More advanced treatments of plume dilution can be found in other references (e.g. Jacobson et al., 2005; Uhrner et al., 2007). Although the 3-D transport model (Jacobson et al., 2005) has an advantage in simulating the plume transport in stage 3 compared to the method used here, it can not resolve the nucleation process happening near the tailpipe and the nanoparticle evolution on the roadway due to its horizontal resolution $(15 \mathrm{~m} \times 15 \mathrm{~m})$. It should be noted that in this study, the dilution ratio at each of these three stages is derived based on some real gaseous species measurements in an exhaust plume and we will show that dividing plume evolution into three-stage dilution yields reasonable agreement with measured on-road particle size distributions.

\subsection{Nanoparticle nucleation and evolution:} a kinetic modeling

A discrete-sectional bin structure (Yu, 2006) is used to represent the size spectra of molecular clusters/particles ranging from molecular size to several micrometers. The formation and evolution of clusters/nanoparticles are simulated kinetically by solving the following set of differential equations (Yu, 2006),

$$
\begin{aligned}
\frac{\partial C_{i, X}}{\partial t}= & l_{i+1, i} \delta_{X, A} \gamma_{i+1, X} C_{i+1, X}-l_{i, i-1} \gamma_{i, X} C_{i, X} \\
& +\sum_{j=1}^{i} \sum_{k=1}^{i-1} f_{j, k, i} \beta_{j, k} N_{j} C_{k, X} \\
& -C_{i, X} \sum_{j=1}^{i \max }\left(1-f_{i, j, i}\right) \beta_{i, j} N_{j}
\end{aligned}
$$

where $i, j, k$ are bin indices, $C_{i, X}$ is the volume concentration of component $X\left(=\mathrm{H}_{2} \mathrm{SO}_{4}, \mathrm{H}_{2} \mathrm{O}\right.$, and other species including organics (low- and semi-volatile, soot and refractory cores) at bin $i, N_{j}$ is the number concentration of cluster/particle at bin $j, \beta_{i, j}$ is the coagulation kernel between particles at bin $i$ and bin $j, \gamma$ is the cluster evaporation rate, $i_{\max }$ is maximum number of bins in the model (set to be 150 in this study), $f_{j, k, i}$ is the volume fraction of intermediate particles (volume $=v_{j}+v_{k}$ ) partitioned into bin $i$, $l_{i+1, i}=\frac{v_{1}}{v_{i+1}-v_{i}}$ is the volume fraction of intermediate particles of volume $v_{i+1}-v_{1, A}$ partitioned into bin $i$, and $\delta_{X, A}$ accounts for the volume of $\mathrm{H}_{2} \mathrm{SO}_{4}$ molecules evaporated from the clusters, and is defined as

$\delta_{X, A}= \begin{cases}v_{i} / v_{i+1}, & \text { if } X=\mathrm{H}_{2} \mathrm{SO}_{4} \\ 1, & \text { if } X \neq \mathrm{H}_{2} \mathrm{SO}_{4}\end{cases}$

In the present study, sulfuric acid and water are the only species involved in nucleation. Organics contribute to the aerosol formation via condensation onto the nucleated particles. The improved kinetic quasi-unary nucleation (KQUN) model (Yu, 2007), in which measured thermochemical properties of $\mathrm{H}_{2} \mathrm{SO}_{4}$ monomers with hydrated sulfuric acid dimers and trimers (Hanson and Lovejoy, 2006) and data from two independent measurements of monomer hydration have been incorporated, has been employed. The improved KQUN model is thermodynamically more robust and predicts binary homogeneous nucleation rates in good agreement with available experimental data. Another advantage of the aforementioned model is that the nanoparticle formation and subsequent evolution are coupled. The coupling allows explicit simulations of the aerosol dynamics (i.e. nucleation, coagulation and condensation) of vehicle-emitted nanoparticles on and near the roadway. Van der Waals forces and fractal geometry are not considered here. Our sensitivity test showed that their effects on coagulation of soot particles with smaller nanoparticles are small in the time scale $(\sim 45 \mathrm{~s})$ considered in the paper. However, their effects may become important for studying plumes with much longer plume age.

Ambient background aerosols were included in our model, and they participate in scavenging of small nanoparticles and $\mathrm{H}_{2} \mathrm{SO}_{4}$ vapor molecules as exhaust mixes with the ambient air. The mean size and undiluted concentration of the ambient background aerosols is assumed to be $\sim 60 \mathrm{~nm}$ in diameter and $10^{4}\left(\mathrm{~cm}^{-3}\right)$, respectively (Kittelson et al., 2004). It is log-normally distributed with sigma assumed to be 1.6. The mean size and concentration of soot particles is assumed to be $50 \mathrm{~nm}$ in diameter and $10^{7} \mathrm{~cm}^{-3}$, respectively (Kittelson et al., 2004). It is a log-normal distribution with sigma set to be 1.8 .

\subsection{Organic condensation}

The volume concentration change of organics ( $X=$ organics) due to cluster/particle condensation and evaporation is calculated using the following set of equations,

$$
\begin{aligned}
& \frac{\partial C_{i, \text { org }}}{\partial t}=\pi V_{\text {org }} f_{\text {corr }} N_{i} r_{i}^{2} v_{\mathrm{org}}\left(P_{\mathrm{org}}-P_{s, \text { org }} A_{\mathrm{kelvin}}\right) \\
& f_{\text {corr }}=\frac{k n_{i}}{0.75+k n_{i}} \\
& A_{\text {kelvin }}=\exp \left(\frac{2 \sigma_{\mathrm{org}} v_{\mathrm{org}}}{k T r_{i}}\right)
\end{aligned}
$$


where $V_{\text {org }}, v_{\text {org }}, P_{\text {org }}, P_{s, \text { org }}$, and $\sigma_{\text {org }}$ are the thermal speed, volume, vapor pressure, saturation vapor pressure, and surface tension of condensing organic species, respectively. $f_{\text {corr }}$ is the correction factor accounting for the transition regime (Seinfeld and Pandis, 1998). $A_{\text {kelvin }}$ is the Kelvin effect and $r_{i}$ is the wet radius of clusters/particles in bin $i$.

It is not feasible to take into account all the organics observed in exhaust due to the large number of species. In this study two types of organics, low volatile organic from lubricating oil (carbon number of 32) and semi-volatile organic from fuel (with carbon number of 24), were simulated. Their surrogates are alkanes, which have been shown to be important for the diesel exhaust evolution (Sakurai et al., 2003). The vapor pressures of these surrogates are similar to those of alkenes of the same carbon number (Makar, 2001). The simplified characterization of the organics should not largely affect the major conclusions concerning the nanoparticle evolution, especially in most cases in which $\mathrm{H}_{2} \mathrm{SO}_{4}$ vapors dominate particle growth.

Raoult's law is not considered in the equation primarily because the majority of the paper deals with situations in which $\mathrm{H}_{2} \mathrm{SO}_{4}$, not organics, contributes to the particle growth. In the case in which organics is important to particle growth (Figs. 3b and 5), we did not consider the Raoult's law because of the complexity of photochemical aging of semivolatile organics in the exhaust (Robinson et al., 2007), the large uncertainties in the concentrations and saturation vapor pressures of semi- and low volatile organics, and simplified treatment of these organics (i.e. divided into two categories) in the current simulations. In order to properly take into account the effect of Raoult's law on particle condensational growth, we need more accurate information on the concentrations and vapor pressures of various types of semiand low- volatile organics, more detailed representations of different organics and more importantly their possible photochemistry pathways. Since this paper focuses mainly on the NP formation mechanisms, not including Raoult's law in condensation growth will not affect the main conclusions of this paper.

\section{Results}

3.1 Effect of enhanced sulfur conversion efficiency on nanoparticle formation

One possible explanation of the nanoparticle formation under ultra-low sulfur fuel conditions is the enhanced sulfur conversion efficiency. The oxidation catalyst in the CRDPFs, for instance, not only oxidizes soot and other hydrocarbons to $\mathrm{CO}_{2}$, but also converts significantly more $\mathrm{SO}_{2}$ into $\mathrm{SO}_{3}$. The $\mathrm{SO}_{3}$ then reacts with $\mathrm{H}_{2} \mathrm{O}$ to form $\mathrm{H}_{2} \mathrm{SO}_{4}$. Thus, sulfur conversion efficiency can be considerably enhanced due to CRDPFs.
Sulfur conversion efficiency $(\varepsilon)$ of after-treatments varies greatly, depending mainly on the exhaust temperature, noble metal and washcoat used in the oxidation catalyst. Based on their gaseous phase $\mathrm{H}_{2} \mathrm{SO}_{4}$ measurements in vehicle exhaust, Arnold et al. (2006) suggested that $\varepsilon$ can be enhanced to be as high as $90 \%$. Similar conclusions have been made in other related studies (Maricq et al., 2002; Kittelson et al., 2006). Giechaskiel et al. (2007) have expressed $\varepsilon$ as function of exhaust temperature by compiling data from different studies. The relationship between $\varepsilon$ and the exhaust temperature used in this study (except Fig. 2) has been adopted from Fig. 8 in Giechaskiel et al. (2007).

Although laboratory studies have indicated that the sulfuric acid is involved in the formation of observed nanoparticles under ultra-low sulfur conditions for vehicles equipped with advanced after-treatments such as CRDPFs, the theoretical assessment of this issue is yet to be performed. In order to understand whether BHN is the nucleation mechanism, we have carried out two case studies. The first one looks into the laboratory study by Vaaraslahti et al. (2005) which focused on the effect of lubricant oil on nanoparticle formation $(\mathrm{FSC}=1 \mathrm{ppm})$. In the second case study, onroad measurements by Kittelson et al. (2006), which studied the effect of diesel exhaust after-treatments on nanoparticle formation $(\mathrm{FSC}=15 \mathrm{ppm}$ ) have been simulated. Both studies were conducted with ultra-low sulfur fuels. A two-stage dilution system was used in Vaaraslahti et al. (2005), while the exhaust was diluted continuously in the work of Kittelson et al. (2006). The cut-off size of the particle size distribution in both measurements was $\sim 3 \mathrm{~nm}$. The key parameters of experimental setups such as exhaust temperature and dilution profile, ambient and dilution air temperature, sulfur content of fuel and lubricating oil were explicitly specified. The detailed experimental setups and key parameters can be found in (Vaaraslahti et al., 2005; Kittelson et al., 2006), and the corresponding parameters used to constrain the present model are given in Table 1.

Figure 1 shows the comparison of the simulated particle size distribution with the observed one from Vaaraslahti et al. (2005). $\varepsilon$ used in the simulations is assumed to be $100 \%$ for exhaust temperature of $750 \mathrm{~K}$. As seen from Fig. 1, the predicted particle size distribution is in good agreement with the measurement, especially in terms of mode peak concentration and mean size. The good agreement in particle size distribution between the model prediction and the observation theoretically demonstrates that even under ultra-low sulfur conditions, $\sim 1 \mathrm{ppm}$ of FSC in this case, BHN remains to be the nucleation mechanism for nanoparticles in the exhaust of vehicles equipped with advanced after-treatments such as CRDPFs.

High value of $\varepsilon$ resulting from exhaust after-treatments is one of the main reasons that BHN produces nanoparticles under ultra-low FSC conditions. $\varepsilon$ depends strongly on exhaust temperature and is hard to measure. Here we show that our model can yield reasonable prediction of 
Table 1. Parameters used for comparisons of model simulation with laboratory studies (Vaaraslahti et al., 2005; Kittelson et al., 2006).

\begin{tabular}{lll}
\hline & Kittelson et al. (2006) & Vaaraslahti et al. (2005) \\
\hline fuel sulfur content (ppm) & 15 & 1 \\
lubricant sulfur content $(\mathrm{ppm})$ & 1300 & 5100 \\
lube oil consumption rate (\%) & 0.5 & 0.5 \\
exhaust temperature (K) & $603.15-643.15$ & 750.15 \\
dilution air temperature (K) & 295.15 & 303.15 \\
Dilution ratio & $400-600$ & Primary 12, secondary 8 \\
residence time (s) & $1 \mathrm{~s}$ in air, 2 s in sampling line & $3 \mathrm{~s}$ in ageing chamber \\
\hline
\end{tabular}

temperature-dependent $\varepsilon$ based on the particle concentration measurements. Figure 2 a shows the particle ( $\mathrm{Dp} \geq 3 \mathrm{~nm}$ ) number concentration from both model simulations and measurements at several exhaust temperatures. The good agreements between the predicted particle number concentrations and the measured ones at all the temperatures are achieved by selecting an appropriate $\varepsilon$ at each temperature. Then we can obtain a profile of $\varepsilon$ at different exhaust temperatures. Figure $2 \mathrm{~b}$ compares the sulfur conversion efficiency obtained with those from Fig. 8 in Giechaskiel et al. (2007). As can be seen from Fig. 2b, the model-derived relationship of the sulfur conversion efficiencies as a function of the exhaust temperature is in good agreement with experimental data. This suggests that our model predicts good temperature dependency of nucleation rates. It can also be used to infer the temperature-dependent $\varepsilon$ of a particular CRDPF by matching the predicted particle number concentrations to the measured ones.

As pointed out earlier, comparisons of the simulation results with measurements show that our model accurately predicts not only the particle size distribution but also the temperature dependence of nucleation rates. Moreover, the good agreement between the theory and experiments gives us a clear indication that $\mathrm{BHN}$ is responsible for the nanoparticle formation in the exhaust of vehicles with CRDPFs running on ultra-low sulfur fuel. These results are encouraging for the further applications of the developed model to the formation and evolution of nanoparticles in the vehicular exhaust diluting in the real atmosphere. Figure 3 shows the evolution of the particle size spectrum as a function of plume ages up to $75 \mathrm{~s}$ under (a) ultra-low sulfur conditions (effective sulfur content $(\mathrm{ESC})=30 \mathrm{ppm}$ with $\mathrm{FSC}=15 \mathrm{ppm}$ and contribution from lube sulfur content (LSC) $=15 \mathrm{ppm}$ ) and (b) high sulfur conditions $(\mathrm{ESC}=330 \mathrm{ppm}$ with $\mathrm{FSC}=330 \mathrm{ppm}$ ) in a winter condition $(T=278 \mathrm{~K}, \mathrm{RH}=60 \%)$. LSC represents sulfur content from the lubricating oil and effective sulfur content is the sum of both FSC and LSC. It is important to note that the sulfur from the lubricating oil has to be accounted for in the case where the ultra-low sulfur fuel is used. The LSC is assumed to be $3000 \mathrm{ppm}$ with the lube oil leaking rate assumed to be $0.5 \%$ (Abdul-Khalek et al., 1998). The sul-

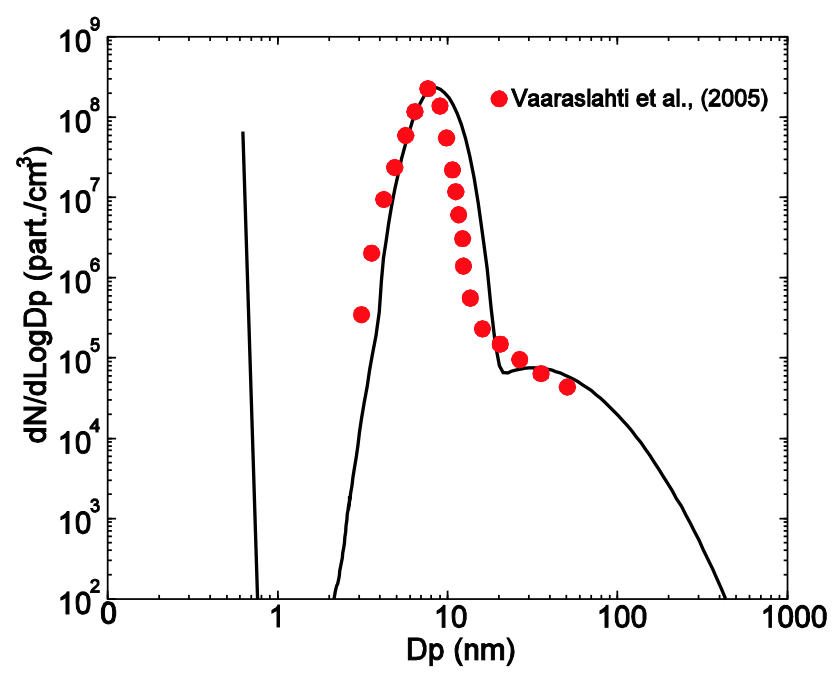

Fig. 1. Comparison between the predicted particle size distribution and measured one from Vaaraslahti et al. (2005). The sulfur to sulfuric acid conversion efficiency $\varepsilon$ used in the simulation is assumed to be $100 \%$ for exhaust temperature of $750 \mathrm{~K}$.

fur conversion efficiency is assumed to be $60 \%$ for Fig. $3 \mathrm{a}$ and $1.4 \%$ for Fig. 3b, respectively. Data shown in Fig. 3a were obtained assuming that CRDPFs efficiently removes all of the organic compounds in the exhaust. This is consistent with recent findings of Vaaraslahti et al. (2004) who have observed a reduction of $90 \%$ in total hydrocarbon concentration for a heavy duty diesel vehicle equipped with CRDPFs. The wind speed is assumed to be $2 \mathrm{~m} / \mathrm{s}$ and the distance of vehicular plume away from centerline of the highway is calculated based on the plume age. A distance of $12 \mathrm{~m}$ from the centerline of the roadway is considered as a border of the roadside, assuming the roadway to be $24 \mathrm{~m}$ in width.

As seen from Fig. 3a, no nucleation happens (dot-dashed curves in black) if vehicles are not equipped with CRDPFs and running with fuel with $\mathrm{FSC}=15 \mathrm{ppm}$; however, significant nucleation occurs when CRDPFs are functioning (solid curves in black). Mode $\mathrm{I}$ is composed exclusively of $\mathrm{H}_{2} \mathrm{SO}_{4}$ $\mathrm{H}_{2} \mathrm{O}$ particles formed via BHN nucleation. Mode III consists 


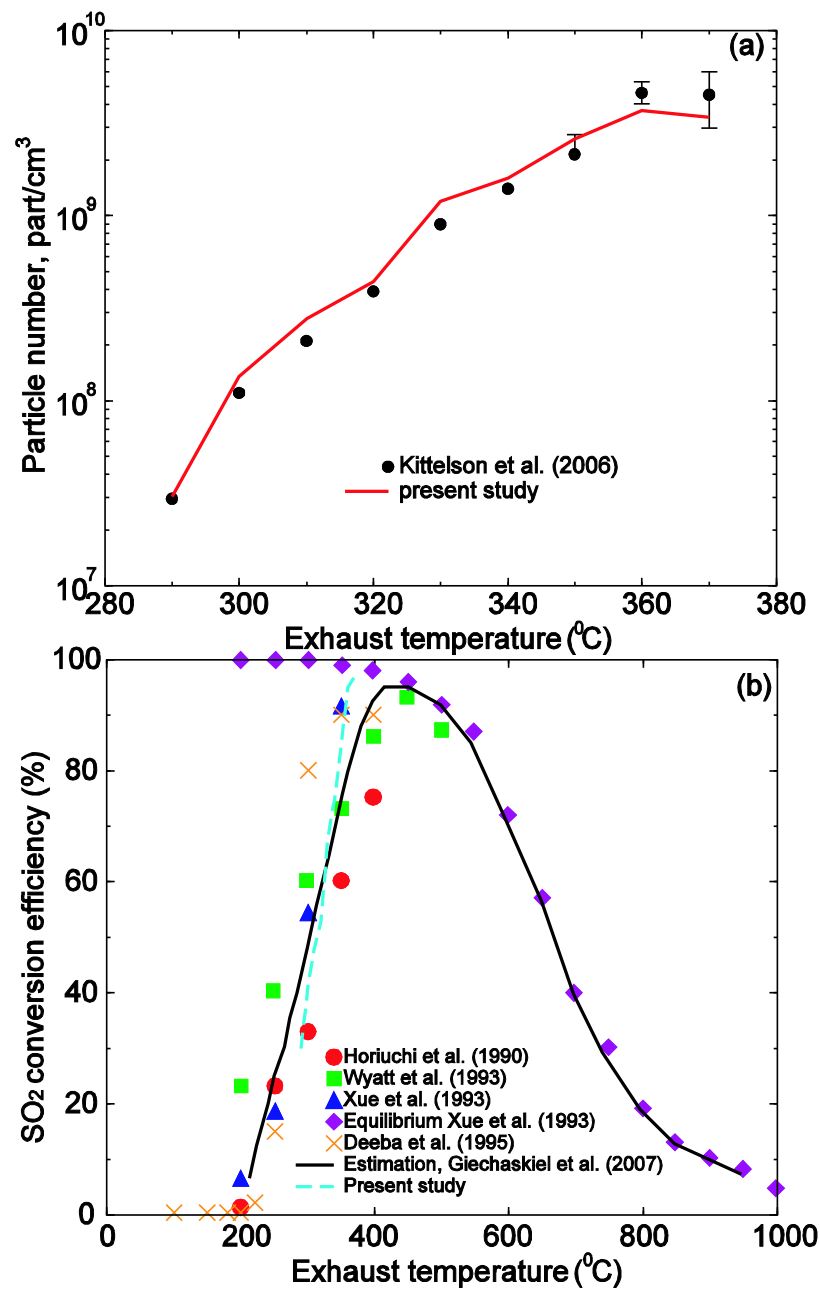

Fig. 2. The effect of exhaust temperatures on (a) dilution corrected number concentrations of nanoparticles $(\mathrm{Dp}>3 \mathrm{~nm}$ ) formed in the vehicle equipped with modern diesel particle filters, and (b) sulfur to sulfuric acid conversion efficiency assumed in our simulation and from other studies. The experimental data (black dots) in panel (a) are from Kittelson et al. (2006). The sulfur conversion efficiencies are adjusted in the model so that the predicted nanoparticle concentrations are close to the measured ones for different exhaust temperatures. The sulfur conversion efficiencies inferred in this way along with numbers reported in other studies are plotted in panel (b) as function of exhaust temperature.

mainly of soot agglomerates and ambient particles. Our model shows that most of the nucleation happens within plume age of $0.1 \mathrm{~s}$. The concentration of particles in Mode I decrease with time mainly due to the atmospheric dilution since then. In addition, a distinct nucleation mode is formed within less than $1 \mathrm{~s}$. The similar time scale has also been observed by Rönkkö et al. (2006) which has shown that the aerosol nucleation mode was formed within $0.45 \mathrm{~s}$.

An apparent difference in the particle size distribution between (a) ultra-low sulfur and (b) high sulfur case is the ex-
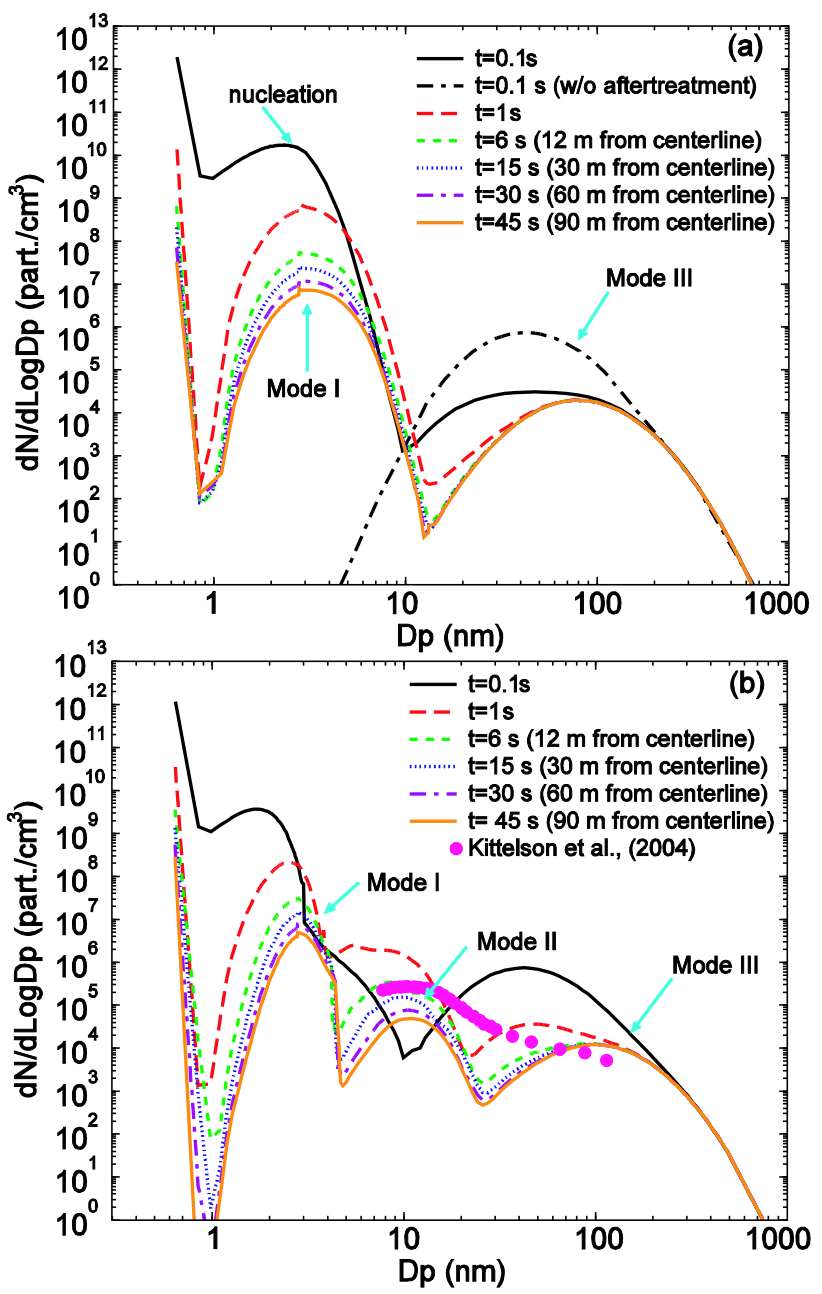

Fig. 3. Nanoparticle formation and evolution as a function of plume ages up to $75 \mathrm{~s}$ under (a) ultra-low sulfur conditions (effective sulfur content $\mathrm{ESC}=30 \mathrm{ppm}$ ) and (b) high sulfur conditions $(\mathrm{ESC}=330 \mathrm{ppm})$ in a winter condition $(T=278 \mathrm{~K}, \mathrm{RH}=60 \%)$. The sulfur conversion efficiency is assumed to be $60 \%$ for panel (a) and $1.4 \%$ for panel (b), respectively. Particle number concentration is not corrected for dilution.

istence of Mode II reported in many recent field measurements. An example of such on-road measurements (from Kittelson et al., 2004) is given in Fig. 3b. This measurement has been chosen because FSC and ambient temperature assumed in our simulation are close to high FSC in Minnesota $(\sim 300-400 \mathrm{ppm})$ and cold ambient temperature during the measurements ( $274 \mathrm{~K}$ to $286 \mathrm{~K}$ ). Due to its large Kelvin Effect, only part of Mode I particles can be activated by semiand low volatile organics and form the Mode II. It is clear from Fig. $3 b$ that our model is able to capture the main features of the observed on-road nucleation mode (Mode II). The mean size of Mode II is close to observed nucleation mode and the predicted peak concentration is in reasonable agreement with the measured one. The comparison with the 
observed on-road measurements should be viewed more as a qualitative one rather than a quantitative one mainly because of the complexity in both plume inter-mixing which is not considered in our model and organic speciation.

As shown in Fig. 3, the nucleation process happens within the first $0.1 \mathrm{~s}$ of plume age. Thereafter, the evolution of nucleation mode particles is dominated by condensation/evaporation and dilution. Coagulation plays a small role at the time scale $(\sim 45 \mathrm{~s})$ considered in this study. However, as plume age increases $(>100 \mathrm{~s})$, the role of coagulation in reducing the number concentration of Mode I becomes much more important as pointed out in other references (e.g. Jacobson and Seinfeld, 2004; Jacobson et al., 2005)

Due to the absence of organics associated with the equipment of CRDPFs in the ultra-low sulfur case (Fig. 3a), the mean size of the nucleation mode (Mode I) is $\sim 3-4 \mathrm{~nm}$. This is much smaller than that shown in Fig. 3b (Model II). This finding is consistent with the measurements reported in Kittelson et al. (2006), which show that the mean sizes of the observed nucleation mode are $\sim 5 \mathrm{~nm}$ or smaller for most exhaust temperatures. Although the mean size of nucleation mode becomes smaller, the number concentration of the nucleation mode (Mode I) under ultra-low sulfur conditions will be at least the same, if not higher, than that of (Mode I+Mode II) under high sulfur conditions due to the enhanced sulfur conversion efficiency and removal of soot agglomerates. This indicates that the effect of reduction in fuel sulfur content on minimizing the vehicular nanoparticle emission is offset by the employment of CRDPFs.

\subsection{Effect of sulfate storage and release on nanoparticle formation}

Besides oxidizing $\mathrm{SO}_{2}$, the diesel oxidation catalyst and/or particulate filter can also adsorb sulfate. Sulfate can also deposit on tailpipe walls. Sulfate may be released due to the saturation of storage sites and/or passage of the high temperature exhaust due to the vehicle acceleration. The sulfate release leads to a considerable increase in the $\mathrm{H}_{2} \mathrm{SO}_{4}$ concentration in exhaust, which makes BHN under ultra-low sulfur conditions possible, even in the case when $\varepsilon$ is low (due to less catalyst oxidation efficiency associated with low exhaust temperature). In the present work, we investigate the extent to which such sulfate storage/release effects may influence the nanoparticle formation in ultra-low sulfur conditions. Assuming that the original $\mathrm{H}_{2} \mathrm{SO}_{4}$ concentration in exhaust to be $\mathrm{C}_{0}$ and that resulting from the sulfur release effect to be $C_{1}$, the storage/release enhance factor (SREF) can be defined as $C_{1} / C_{0}$. Clearly, the bigger the SREF, the higher the $\mathrm{H}_{2} \mathrm{SO}_{4}$ concentration in raw exhaust.

It is difficult to predict the amount of sulfate deposited on exhaust after-treatments or tailpipe, and no direct measurements on SREF are available at the present time. SREF depends on several factors, such as type and mass of washcoat, and exhaust temperature. Arnold et al. (2006) also at-

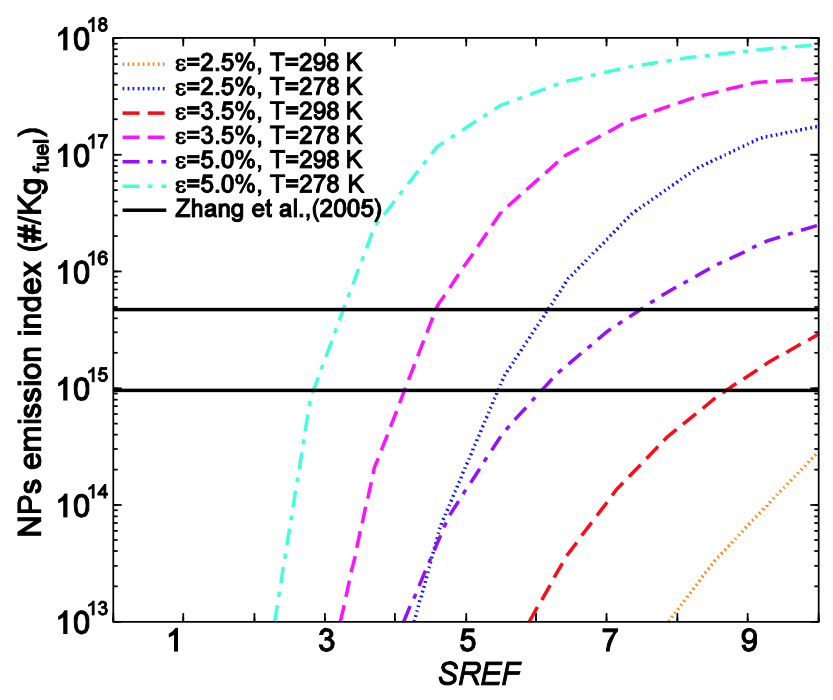

Fig. 4. Dependence of dilution corrected nanoparticle emission indices on SREF at 3 different $\varepsilon \mathrm{s}(2.5 \%, 3.5 \%$, and $5.0 \%)$ at ambient $\mathrm{RH}=50 \%$ in winter $(T=278 \mathrm{~K})$ and summer $(T=298 \mathrm{~K})$ conditions. The ESC is assumed to be $30 \mathrm{ppm}$.

tributed the occasionally measured high $\varepsilon$ to the release of sulfate from oxidation catalyst at high exhaust temperature. Since both the sulfur conversion process and the sulfate release effect may affect gaseous phase $\mathrm{H}_{2} \mathrm{SO}_{4}$ concentration, it is difficult to figure out whether it is enhanced oxidation or sulfate release that caused the observed high $\varepsilon$. However, we can get an upper limit of SREF which is calculated to be 10 based on Arnold et al.'s measurements by assuming that the sulfate release leads to the observed high $\varepsilon$.

Figure 4 shows the predicted nanoparticle emission indices as a function of SREF at 3 different $\varepsilon$ s at two ambient temperatures ( $278 \mathrm{~K}$ and $298 \mathrm{~K}$ ). The ESC is assumed to be $30 \mathrm{ppm}$. Two solid parallel lines from Zhang et al. (2005) represent lower and upper limits of the calculated nanoparticle emission index based on near road measurements (Zhu et al., 2002) in California. We consider any value above the lower line to be significant. In summertime, the sulfur release effect cannot produce significant nanoparticles for the $\varepsilon=2.5 \%$ case. However, this effect becomes important as $\varepsilon$ increases. SREF must have at least a value of 7 and 9 in order for BHN to produce significant amount of nanoparticles for cases of $\varepsilon=5.0 \%$ and $3.5 \%$, respectively. However, as ambient temperature decreases to $278 \mathrm{~K}$, SREF needed to produce significant nanoparticles decreases by more than a factor of 2 for $\varepsilon=3.5 \%$ and $5.0 \%$. This suggests that the sulfur release effect on nanoparticle production become more significant in winter conditions. 

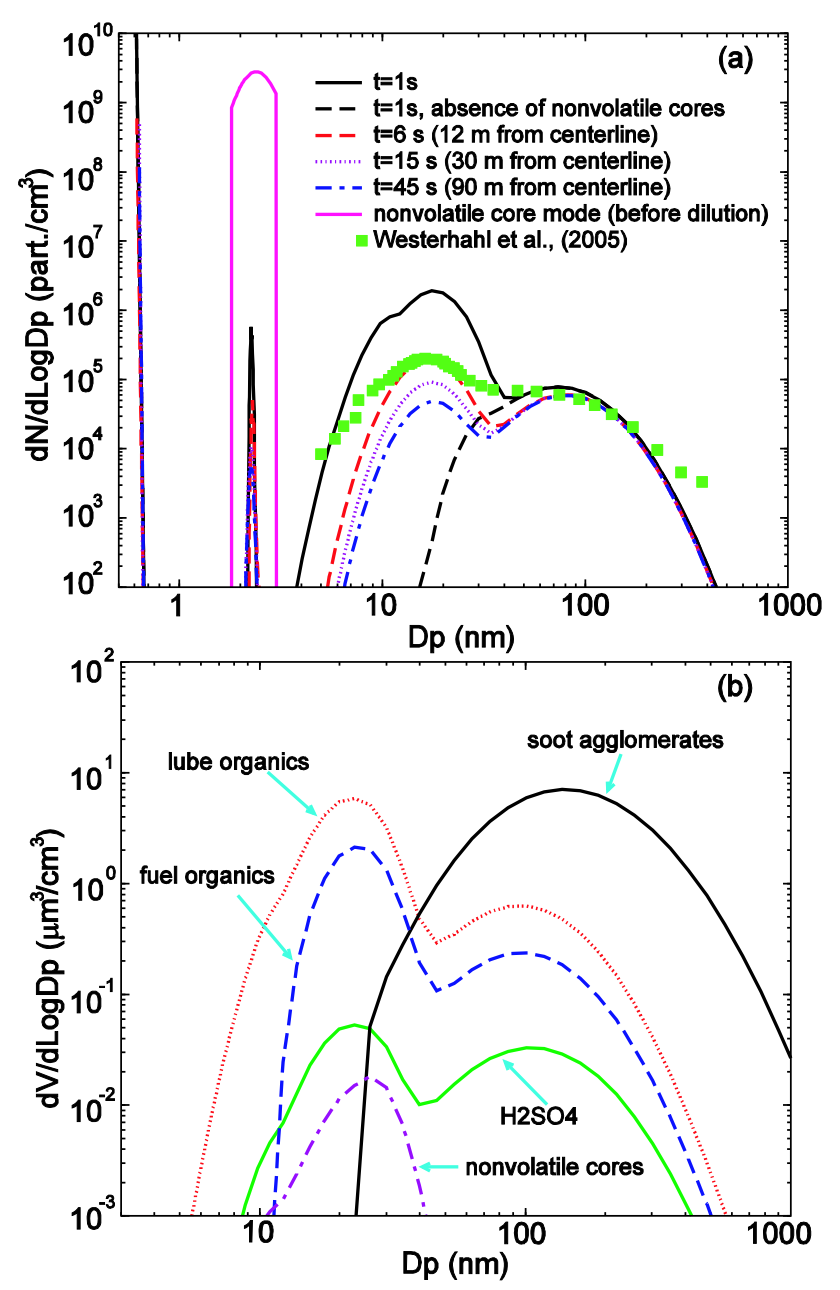

Fig. 5. (a) Evolution of nanoparticle size distributions at four selected plume ages with the presence of non-volatile cores, and (b) volume size distributions for different components at plume age of $1 \mathrm{~s}$. The ambient $T$ and $\mathrm{RH}$ are $295 \mathrm{~K}$ and $60 \%$, respectively. $\mathrm{ESC}=50 \mathrm{ppm}$ and $\varepsilon=2.5 \%$. The particle number and volume size distribution is not corrected for dilution.

\subsection{Role of non-volatile cores in the formation of observed nanoparticles}

A large number of systematic field measurements on the characterization of vehicle-emitted nanoparticles in California have been carried out in the past few years (Zhu et al., 2002, 2004, 2006; Kuhn et al., 2005, 2005; Sardar et al., 2005; Westerdahl et al., 2005; Phuleria et al., 2007). While a lot of useful data on the particle size distribution, nanoparticle evolution process, and particle compositions have been reported, little information on nanoparticle formation mechanism has been revealed. Although generally California fuel has FSC of $\sim 50 \mathrm{ppm}$, a key difference in nanoparticle formation between California case and ultra-low sulfur cases discussed earlier lies in the availability of CRDPFs. To our knowledge, no CRDPFs were employed during the time pe- riods when those field campaigns were conducted. Low sulfur conversion efficiency is therefore expected for vehicles without CRDPFs. In order to address the questionsWhat could be the possible nanoparticle formation mechanism in California and could BHN be an essential nucleation source, we have applied the aerosol model to simulate nanoparticle formation under California conditions (i.e. low sulfur fuel and no CRDPFs) as to gain some insights into the nanoparticle formation mechanism. The presence of a mode of nanometer-sized non-volatile cores is considered. The existence of non-volatile cores has been long observed in a number of field and laboratory studies (Sakurai et al., 2003; Kittelson et al., 2006; Rönkkö et al., 2007). For example, Sakurai et al. (2003) pointed out that $\sim 12$ and $30 \mathrm{~nm}$ particles did not completely evaporate even if they were heated up to $\sim 473 \mathrm{~K}$ and sizes of residual non-volatile cores were as small as $\sim 2-3 \mathrm{~nm}$. The existence of non-volatile fractions of sampled nanoparticles have also been pointed out in their later field measurements (Kuhn et al., 2005; Biswas et al., 2007). In addition, Kittelson et al. (2006) observed a non-volatile mode with mean size of $\sim 10 \mathrm{~nm}$ at engine idle condition. More recently, Rönkkö et al. (2007) found that sampled nanoparticles consist of organic coated non-volatile cores which have been formed before the dilution process.

Figure 5a shows the evolution of nanoparticles as a function of the plume age with the assumed mode of non-volatile cores for vehicles running on low sulfur fuel $(\mathrm{ESC}=50 \mathrm{ppm}$ with $35 \mathrm{ppm}$ of FSC and $15 \mathrm{ppm}$ of LSC). For comparison purposes, a case without non-volatile cores is also shown (black-dashed line Fig. 5a). The non-volatile particles are assumed to be in the range of $1.8 \mathrm{~nm}-3 \mathrm{~nm}$ in diameter, which is consistent with recent measurements of Sakurai et al. (2003). The number concentration of non-volatile cores is assumed to be $3 \times 10^{8} \mathrm{~cm}^{-3}$ before dilution. It is important to note that the actual size range and concentrations of nonvolatile core are expected to depend strongly on soot concentration, engine operation conditions, and fuel and lube oil compositions (Rönkkö et al., 2007). No sulfur storage/release effect is considered in these simulations. For the assumed ESC and sulfur conversion efficiency, no nucleation mode particles were formed via BHN in the absence of nonvolatile cores. This may indicate that $\mathrm{BHN}$ is not responsible for nanoparticle formation in California conditions. However, the presence of non-volatile cores leads to the formation of a clear nucleation mode with a mean size $\sim 20 \mathrm{~nm}$. The predicted particle size distribution is in reasonable agreement with the on-road particle size distribution observed in Los Angeles by Westerhahl et al. (2005) at the ambient temperature of $\sim 294 \mathrm{~K}$. As pointed out earlier, the comparison with the observed on-road measurements should be viewed more as a qualitative one rather than a quantitative one mainly because of the complexity in both plume inter-mixing, which is not considered in our model, and organic speciation. Our simulations show that most of the non-volatile cores are activated. We found that organic compounds, rather than $\mathrm{H}_{2} \mathrm{SO}_{4}$, 
are responsible for the activation of the non-volatile core mode. In other words, $\mathrm{H}_{2} \mathrm{SO}_{4}$ concentration under low sulfur conditions ( $\mathrm{FSC}=50 \mathrm{ppm}$ ) is not high enough to promote the growth of the non-volatile core mode to larger sizes that are $\sim 20 \mathrm{~nm}$. This finding is consistent with recent studies (Vaaraslahti et al., 2005; Rönkkö et al., 2007) which showed no clear effect of FSC on nucleation mode particles. This is different from cases of both high sulfur fuel and ultra-low sulfur fuel with CRDPFs. In those cases, nucleation mode is sensitive to $\mathrm{FSC}$ because of the high concentration of $\mathrm{H}_{2} \mathrm{SO}_{4}$ due to either the high fuel sulfur content or enhanced sulfur conversion efficiency.

Figure $5 b$ shows the composition of particles of various sizes at $1 \mathrm{~s}$ of plume age. Similarly to the case of high sulfur content, organics contribute to the majority mass of the nucleation mode. The volume fraction of non-volatile cores is smaller than that of $\mathrm{H}_{2} \mathrm{SO}_{4}$ and accounts for less than $1 \%$ of total mass of nucleation mode particles. This is consistent with findings of Biswas et al. (2007) who showed that for $20 \mathrm{~nm}$ particles, non-volatile cores account for less than $3 \%$ of particle mass. Although the contribution of non-volatile cores to the nanoparticle mass is negligible, they are a source of the observed nucleation modes. It is important to note that the entire nucleation mode will still disappear (i.e. become undetectable) when these particles are passed through a thermal denuder due to the small mass fraction of solid component. In other words, a complete disappearance of entire observed nucleation mode may not necessarily be an indicator of absence of nanometer-sized non-volatile cores.

\section{Summary and discussion}

A comprehensive modeling study of possible causes of nanoparticle formation under ultra-low sulfur conditions has been carried out using a size- and composition- resolved aerosol microphysics model with an updated binary homogeneous nucleation (BHN) scheme. A good agreement of the predicted particle size distribution and temperature dependences of nucleation rates with experiments leads us to conclude that BHN remains to be the nucleation mechanism of nanopaticle formation for vehicles equipped with CRDPFs and running on ultra-low sulfur fuel. We have shown that such vehicles emit at least the same, if not higher, number concentrations of nanoparticles than those without CRDPFs and running on high sulfur fuel. We also found that the sulfate storage/release effect can lead to a significant nanoparticle production under favorable conditions. This effect becomes more significant as the ambient temperature decreases. These findings lead us to conclude that although CRDPFs are effective in reducing the mass of vehicular emissions, they offset the positive effects of the reduced fuel sulfur contents on the nanoparticle formation and significantly enhance the number concentrations of nanoparticles in vehicular emissions. Moreover, higher nanoparticle number concentrations are expected when the enhanced sulfur conversion and sulfur release effect takes place simultaneously.

Our simulations also showed that most of nucleation events happen within $0.1 \mathrm{~s}$ of plume age and that a clear nucleation mode is developed within $1 \mathrm{~s}$ of plume age. Coagulation and dilution with or without organic condensation can change the particle size distribution at latter stages. We found that the mean size of nucleation mode becomes smaller because the total organic carbon concentration in raw exhaust can be significantly removed by CRDPFs. Smaller in size but of high number concentration, the nucleation mode has the lifetime of $\sim 300 \mathrm{~s}$ due to scavenging by ambient aerosols. The ambient existing particle number concentration of $10^{4}\left(\mathrm{~cm}^{-3}\right)$ and coagulation kernel of $\sim 3 \times 10^{-7}\left(\mathrm{~cm}^{3} / \mathrm{s}\right)$ of nanoparticles $(\sim 2-3 \mathrm{~nm})$ with larger soot or ambient particles $(\sim 100 \mathrm{~nm})$ due to Brownian motion at room temperature were used in the calculations. The present results lead us to conclude that the vehicle-emitted nanoparticles will affect not only residents living near the roadways but also those who live several hundred meters away. The strength of the effect also depends on wind speed and atmospheric dilution.

In addition, we have shown that instead of BHN, the nonvolatile cores are the source of observed nucleation mode in California, where low sulfur fuel is used and vehicles are not equipped with CRDPFs. We found that organics, rather than $\mathrm{H}_{2} \mathrm{SO}_{4}$, contribute to the growth of non-volatile particles that may explain the observed on-road nucleation mode. Nonvolatile cores that are as small as $\sim 2-3 \mathrm{~nm}$ in diameter are able to grow to sizes larger than $10 \mathrm{~nm}$ by taking up the low and semi-volatile organics. The importance of organics in controlling particle growth has been pointed out in a number of references (e.g. Zhang et al., 2004; Jacobson et al., 2005). No valuable information on the formation mechanism of these non-volatile cores is available at the present time. Recent studies suggest that non-volatile cores may be formed due to nucleation of metal oxides or heavy hydrocarbons inside the engine cylinder (Vaaraslahti et al., 2004; Kittelson et al., 2006). Their formation also depends on the engine load and availability of CRDPFs because non-volatile cores were often observed at low engine loads for vehicles without CRDPFs. Kittelson et al. (2006) suggest that low soot surface areas resulting from low engine loads may promote the metal oxide nucleation inside the cylinder. Further research is needed to investigate the formation of the nanometer-sized non-volatile cores.

Acknowledgements. This work was supported by the National Science Foundation under grant ATM 0618124 and the New York State Energy Resource and Development Agency.

Edited by: S. Pandis 


\section{References}

Abdul-Khalek, I. S., Kittelson, D. B., Graskow, B. R., Wei, Q., and Brear, F.: Diesel exhaust particle size: Measurement issues and trends, SAE J-Automot. Eng., 980525, 81-93, 1998.

Arnold, F., Pirjola, L., Aufmhoff, H., Schuck, T., Lahde, T., and Hameri, K.: First gaseous sulfuric acid measurements in automobile exhaust: Implications for volatile nanoparticle formation, Atmos. Environ., 40, 7097-7105, 2006.

Biswas, S., Ntziachristos, L., Moore, K. F., and Sioutas, C.: Particle volatility in the vicinity of a freeway with heavy-duty diesel traffic, Atmos. Environ., 41, 3479-3493, 2007.

Carbajal-Arroyo, L., Barraza-Villarreal, A., Durand-Pardo, R., Moreno-Macias, H., Espinoza-Lain, R., Chiarella-Ortigosa, P., and Romieu, I.: Impact of traffic flow on the asthma prevalence among school children in Lima, Peru, J. Asthma, 44, 197-202, 2007.

Du, H. and $\mathrm{Yu}$, F.: Role of the binary $\mathrm{H}_{2} \mathrm{SO}_{4}-\mathrm{H}_{2} \mathrm{O}$ homogeneous nucleation in the formation of volatile nanoparticles in the vehicular exhaust, Atmos. Environ., 40, 7579-7588, 2006.

Gauderman, W. J., Vora, H., McConnell, R., Berhane, K., Gilliland, F., Thomas, D., Lurmann, F., Avol, E., Kunzli, N., Jerrett, M., and Peters, J.: Effect of exposure to traffic on lung development from 10 to 18 years of age: a cohort study, Lancet, 369, 571-577, 2007.

Giechaskiel, B., Ntziachristos, L., Samaras, Z., Casati, R., Scheer, V., and Vogt, R.: Effect of speed and speed-transition on the formation of nucleation mode particles from a light duty diesel vehicle, SAE J-Automot. Eng., 01, 1110, 307-319, 2007.

Hanson, D. R. and Lovejoy, E. R.: Measurement of the thermodynamics of the hydrated dimer and trimer of sulfuric acid, J. Phys. Chem. A, 110, 9525-9528, 2006.

Jacobson, M. Z. and Seinfeld, J. H.: Evolution of nanoparticle size and mixing state near the point of emission, Atmos. Environ., 38, 1839-1850, 2004.

Jacobson, M. Z., Kittelson, D. B., and Watts, W. F.: Enhanced coagulation due to evaporation and its effect on nanoparticle evolution, Environ. Sci. Technol., 39, 9486-9492, 2005.

Kittelson, D. B., Kadue, P. A., Scherrer, H. C., and Loverien, R. E.: Characterization of diesel particle in the atmosphere, CRC, AP-2 Project Group, 1988.

Kittelson, D. B., Watts, W. F., and Johnson, J. P.: Nanoparticle emissions on Minnesota highways, Atmos. Environ., 38, 9-19, 2004.

Kittelson, D. B., Watts, W. F., and Johnson, J. P.: On-road and laboratory evaluation of combustion aerosols - Part1: Summary of diesel engine results, J. Aerosol Sci., 37, 913-930, 2006a.

Kittelson, D. B., Watts, W. F., Johnson, J. P., Rowntree, C., Payne, M., Goodier, S., Warrens, C., Preston, H., Zink, U., Ortiz, M., Goersmann, C., Twigg, M. V., Walker, A. P., and Caldow, R.: On-road evaluation of two Diesel exhaust aftertreatment devices, J. Aerosol Sci., 37, 1140-1151, 2006b.

Kuhn, T., Biswas, S., Fine, P. M., Geller, M., and Sioutas, C.: Physical and chemical characteristics and volatility of PM in the proximity of a light-duty vehicle freeway, Aerosol Sci. Technol., 39, 347-357, 2005a.

Kuhn, T., Biswas, S., and Sioutas, C.: Diurnal and seasonal characteristics of particle volatility and chemical composition in the vicinity of a light-duty vehicle freeway, Atmos. Environ., 39, 7154-7166, 2005b.

Kuhn, T., Krudysz, M., Zhu, Y., Fine, P. M., Hinds, W. C., Froines,
J., and Sioutas, C.: Volatility of indoor and outdoor ultrafine particulate matter near a freeway, J. Aerosol Sci., 36, 291-302, 2005c.

Makar, P. A.: The estimation of organic gas vapour pressure, Atmos. Environ., 35, 961-974, 2001.

Maricq, M. M., Chase, R. E., Xu, N., and Laing, P. M.: The Effects of the Catalytic Converter and Fuel Sulfur Level on Motor Vehicle Particulate Matter Emissions: Light Duty Diesel Vehicles, Environ. Sci. Technol., 36, 283-289, 2002.

Meng, Y. Y., Wilhelm, M., Rull, R. P., English, P., and Ritz, B.: Traffic and outdoor air pollution levels near residences and poorly controlled asthma in adults, Ann. Allerg. Asthma Im., 98, 455-463, 2007.

Phuleria, H. C., Sheesley, R. J., Schauer, J. J., Fine, P. M., and Sioutas, C.: Roadside measurements of size-segregated particulate organic compounds near gasoline and diesel-dominated freeways in Los Angeles, CA, Atmos. Environ., 41, 4653-4671, 2007.

Robinson, A. L., Donahue, N. M., Shrivastava, M. K., Weitkamp, E. A., Sage, A. M., Grieshop, A. P., Lane, T. E., Pierce, J. R., and Pandis, S. N.: Rethinking organic aerosols: Semivolatile emissions and photochemical aging, Science, 315, 1259-1262, 2007.

Rönkkö, T., Virtanen, A., Kannosto, J., Keskinen, J., Lappi, M., and Pirjola, L.: Nucleation mode particles with a nonvolatile core in the exhaust of a heavy duty diesel vehicle, Environ. Sci. Technol., 41, 6384-6389, 2007.

Rundell, K. W., Hoffman, J. R., Caviston, R., Bulbulian, R., and Hollenbach, A. M.: Inhalation of ultrafine and fine particulate matter disrupts systemic vascular function, Inhal. Toxicol., 19, 133-140, 2007.

Sakurai, H., Tobias, H. J., Park, K., Zarling, D., Docherty, K. S., Kittelson, D. B., McMurry, P. H., and Ziemann, P. J.: On-line measurements of diesel nanoparticle composition and volatility, Atmos. Environ., 37, 1199-1210, 2003.

Sardar, S. B., Fine, P. M., Mayo, P. R., and Sioutas, C.: Sizefractionated measurements of ambient ultrafine particle chemical composition in Los Angeles using the NanoMOUDI, Environ. Sci. Technol., 39, 932-944, 2005.

Seinfeld, J. H. and Pandis, S. N.: Atmospheric Chemistry and Physics: From Air Pollution to Climate Change, New York, NY, Wiley, 1998.

Shi, J. P., Harrison, R. M., Evans, D. E., Alam, A., Barnes, C., and Carter, G.: A Method for measuring particle number emissions from vehicles driving on the road, Environ. Technol., 23, 1-14, 2002.

Uhrner, U., von Löwis, S., Vehkamäki, H., Wehner, B., Bräsel, S., Hermann, M., Stratmann, F., Kulmala, M., and Wiedensohler, A.: Dilution and aerosol dynamics within a diesel car exhaust plume-CFD simulations of on-road measurement conditions. Atmos. Environ. 41, 7440-7461, 2007.

Vaaraslahti, K., Keskinen, J., Giechaskiel, B., Solla, A., Murtonen, T., and Vesala, H.: Effect of lubricant on the formation of heavy-duty diesel exhaust nanoparticles, Environ. Sci. Technol., 39, 8497-8504, 2005.

Vaaraslahti, K., Virtanen, A., Ristimaki, J., and Keskinen, J.: Nucleation mode formation in heavy-duty diesel exhaust with and without a particulate filter, Environ. Sci. Technol., 38, 48844890, 2004.

Westerdahl, D., Fruin, S., Sax, T., Fine, P. M., and Sioutas, C.: 
Mobile platform measurements of ultrafine particles and associated pollutant concentrations on freeways and residential streets in Los Angeles, Atmos. Environ., 39, 3597-3610, 2005.

Wold, L. E., Simkhovich, B. Z., Kleinman, M. T., Nordlie, M. A., Dow, J. S., Sioutas, C., and Kloner, R. A.: In vivo and in vitro models to test the hypothesis of particle-induced effects on cardiac function and arrhythmias, Cardiovasc. Toxicol., 6, 69-78, 2006.

Yu, F.: From molecular clusters to nanoparticles: Secondgeneration ion-mediated nucleation model, Atmos. Chem. Phys., 6, 5193-5211, 2006,

http://www.atmos-chem-phys.net/6/5193/2006/.

$\mathrm{Yu}, \mathrm{F}$.: Improved quasi-unary nucleation model for binary $\mathrm{H}_{2} \mathrm{SO}_{4}$ $\mathrm{H}_{2} \mathrm{O}$ homogeneous nucleation, J. Chem. Phys., 127, 054301, doi:10.1063/1.2752171, 2007.
Zhang, K. M., Wexler, A. S., Zhu, Y. F., Hinds, W. C., and Sioutas, C.: Evolution of particle number distribution near roadways. Part II: The 'Road-to-Ambient' process, Atmos. Environ., 38, 66556665, 2004.

Zhu, Y., Hinds, W. C., Kim, S., Shen, S., and Sioutas, C.: Study of ultrafine particles near a major highway with heavy-duty diesel traffic, Atmos. Environ., 36, 4323-4335, 2002.

Zhu, Y., Hinds, W. C., Shen, S., and Sioutas, C.: Seasonal trends of concentration and size distribution of ultrafine particles near major highways in Los Angeles, Aerosol Sci. Technol., 38, 513, 2004.

Zhu, Y., Kuhn, T., Mayo, P., and Hinds, W. C.: Comparison of daytime and nighttime concentration profiles and size distributions of ultrafine particles near a major highway, Environ. Sci. Technol., 40, 2531-2536, 2006. 